Revista de

Contabilidade e

Organizações

www.rco.usp.br
DOI: http://dx.doi.org/10.11606/rco.v10i28.119480
Journal of

Accounting and

Organizations

www.rco.usp.br

\title{
Relação entre o nível de intangibilidade dos ativos e o valor de mercado das empresas
}

\author{
Franciele Medrado ${ }^{\mathrm{a}}$; Gilson Cella ${ }^{\mathrm{a}}$, João Vicente Pereira ${ }^{\mathrm{a}}$; José Alves Dantas ${ }^{\mathrm{a}}$
}

${ }^{a}$ Universidade de Brasilia

\section{Informações do Artigo}

Histórico do Artigo

Recebido: 22 de agosto de 2016

Aceito: 07 de dezembro de 2016

\section{Palavras-chave:}

Ativos intangíveis.

Market-to-book.

Índice de intangibilidade dos ativos.

Valor de mercado.

\begin{abstract}
Resumo
Este estudo tem por objetivo avaliar, no âmbito do mercado de capitais brasileiro, a associação entre o nível de intangibilidade dos ativos e o valor de mercado das ações das empresas. O pressuposto é que modelos de negócio baseados significativamente em conhecimento e tecnologias devem promover vantagens competitivas, o que deve se refletir no valor de mercado das empresas. Para a realização dos testes empíricos foram consideradas as informações trimestrais, de 2008 a 2014, das empresas que compõem o índice IBrX 100 da BM\&FBovespa. Os resultados da estimação de modelos de regressão de dados em painel com efeitos fixos seccionais e duplo efeitos fixos confirmaram a associação positiva e estatisticamente relevante entre o nível de intangibilidade dos ativos e o grau de valorização das ações, representado pela relação market-to-book. Isso demonstra que maiores investimentos em ativos intangíveis proporcionam uma valorização do preço de mercado da empresa.
\end{abstract}

Copyright (C) 2016 FEA-RP/USP. Todos os direitos reservados

\section{INTRODUÇ̃̃̃O}

Os ativos intangíveis representam elementos associados a investimentos, à inovação científica e tecnológica e à criação de valor. Por essa razão, é natural se supor que tenham importância na formação do valor econômico das empresas, sob uma visão estratégica de recursos. De acordo com o Pronunciamento Técnico CPC 04 (Rl), os ativos intangíveis são ativos não monetários identificáveis sem substância física, geralmente são associados à aquisição, ao desenvolvimento, à manutenção e aprimoramento de elementos sem substância física como conhecimento científico ou técnico, implantação de novos processos ou sistemas, licenças, propriedade intelectual, conhecimento mercadológico, nome, reputação, imagem e marcas registradas. A condição para o reconhecimento como ativos intangíveis é de que esses itens sejam identificáveis, controlados e geradores de benefícios econômicos futuros.

Em linha com esse preceito, Kayo (2002) destaca que, nos Estados Unidos da América (EUA), resultados econômicos esperados advindos de ativos com ausência de substância física demonstram vantagem competitiva que cria valor sustentado para a empresa, a partir de recursos raros e insubstituíveis, que poderão levar à geração de lucros anormais, evidenciados pelo crescimento do índice baseado na diferenciação entre o valor contábil e o valor de mercado das ações.

De acordo com Ritta e Ensslin (2010), os ativos intangíveis configuram-se como os novos propulsores do ambiente econômico das empresas, devido aos modelos de negócios contemporâneos serem baseados relevantemente em conhecimento e tecnologias, levando as empresas a maiores necessidades de investimentos em ativos intangíveis, objetivando uma manutenção das suas vantagens competitivas.

Enquanto os investimentos em ativos tangíveis proporcionam retorno claramente identificável, pois os equipamentos, plantas e tecnologias estão disponíveis e precificados no mercado, os investimentos em ativos intangíveis, por suas características e peculiaridades, nem sempre estão disponíveis no mercado, sendo muitas vezes desenvolvidos pelas empresas para atender suas características específicas e seu retorno nem sempre é de

Autor Correspondente: Tel (61) 3107-0812

E-mail: francielecristinamedrado@gmail.com (F. Medrado); gilson.bsb2@gmail.com (G. Cella); joao.vicentep@gmail.com (J. V. Pereira);

josealvesdantas@unb.br (J. A. Dantas).

Programa de Pós-Graduação em Contabilidade - PPGCONT - Faculdade de Economia, Administração e Contabilidade - FACE - Universidade de Brasília -

Campus Darcy Ribeiro - Prédio da FACE - Asa Norte - CEP: 70910-900 - Brasília - DF. 
fácil mensuração.

Os ativos intangíveis ultrapassam os ativos tangíveis em muitas empresas, tanto em valor quanto em contribuição para o crescimento, mas frequentemente são reconhecidos como despesas nos relatórios financeiros e, portanto, permanecem ausentes dos balanços das empresas (LEV, 2001). A mudança de foco em relação aos ativos intangíveis, a partir de 1960, 1970 e 1980, está relacionada com o valor das empresas em relação ao seu valor patrimonial líquido. A taxa média do market-to-book das 500 empresas S\&P aumentou continuamente desde a década de 80, atingindo uma relação de seis vezes em março de 2001. A interpretação de Lev (2001) é que em cada seis dólares de valor de mercado, um dólar está registrado como ativos tangíveis e o restante representam ativos intangíveis.

Seguindo essa perspectiva, no Brasil alguns estudos associam investimentos das empresas em intangíveis com o patrimônio líquido e com o aumento do valor das ações, pela criação da expectativa de geração de caixa futuro (KAYO; FAMÁ, 2010; RITTA et al., 2010; COLAUTO; NASCIMENTO; AVELINO, 2009).

Considerando esse contexto, o presente estudo tem por objetivo avaliar, no âmbito do mercado de capitais brasileiro, a associação entre o nível de intangibilidade dos ativos e a valorização das empresas, ou seja, se as empresas que intensificam seus recursos em ativos intangíveis são mais bem percebidas pelo mercado na avaliação de suas ações. A pesquisa parte da premissa de que uma maior participação dos ativos intangíveis na estrutura de patrimônio da empresa se relaciona positivamente com indicadores de valor de mercado da entidade - a relação entre o valor de mercado e o valor registrado na contabilidade (market-to-book), em particular. Para a realização dos testes empíricos são consideradas as informações trimestrais de 2008 a 2014 das empresas listadas na BM\&FBovespa que constituem o indicador IBRX 100.

A principal motivação para o estudo surge notadamente pela sua aplicabilidade, cujas conclusões contribuirão para o processo de decisão empresarial. Tais resultados sobre a valoração de mercado do ativo intangível interessam aos principais usuários da informação contábil, tais como investidores, administradores, credores ou legisladores. A inovação desta pesquisa está na forma de apurar a variável dependente Índice de Intangibilidade dos Ativos (IIA), obtendo resultados que também contribuem para os estudos sobre ativos intangíveis e sobre sua influência na criação de valor das empresas. O avanço da literatura sobre os determinantes do valor de mercado das empresas em relação ao valor contábil, tem aumentado significativamente pelas mudanças provocadas advindas da modernização das regras para acompanhar a evolução e inovação dos negócios, mas há ainda oportunidades de desenvolvimento, notadamente em relação a itens sobre os quais persistem discussões relativas à identificação, ao reconhecimento e à mensuração, como é o caso dos ativos intangíveis oriundos de sistemas, licenças, propriedades intelectuais, imagem e marcas registradas pelas empresas.

Além da introdução, que contextualiza o tema e define os propósitos da pesquisa, o trabalho contempla: a discussão dos aspectos teóricos e a revisão de literatura que dão suporte ao desenvolvimento do estudo (Seção 2); a definição dos procedimentos metodológicos para a realização dos testes empíricos (Seção 3); a apresentação e discussão dos resultados (Seção 4); e a síntese das principais conclusões e sugestões para pesquisas futuras (Seção 5).

\section{REFERENCIAL TEÓRICO}

\subsection{Inovações tecnológicas nas empresas}

A transição para a economia do conhecimento verificada nas últimas décadas fez com que a composição da estrutura patrimonial das empresas se alterasse, demonstrando maior preocupação na realização de investimentos em tecnologia. Segundo Tigre (2005), a Teoria da Firma desenvolveu-se a partir de 1920 com questionamentos sobre o realismo e o modelo neoclássico. O paradigma novo, instituído por inovações técnicas e organizacionais, forneceu uma nova direção para a organização interna da firma e sua interação com o mercado, fato que alterou a dinâmica de acumulação de capital. Com a elevação da complexidade das organizações, advinda do avanço tecnológico, das técnicas de gestão e do surgimento de empresas modernas, essa teoria obteve grande atenção e tornou-se foco de estudos (CAMARGOS; COUTINHO, 2008).

Nesse contexto, a Teoria da Firma seria adequada para explicar a inserção da tecnologia na realidade das empresas modernas, fato este que contribui para o incremento de ativos intangíveis na economia. Ao haver 
a necessidade de discussão acerca de diferentes segmentos de empresas, podendo oferecer embasamentos sobre a organização da produção e os custos de transação inerentes ao desempenho de qualquer atividade, levando ao surgimento de novas firmas.

A contribuição de Coase (1992) foi de grande relevância para o desenvolvimento de novas abordagens sobre a Teoria da Firma, ao criticar que as firmas têm sido tratadas pela teoria econômica como "caixas-pretas", pois aparecem em qualquer mercado, mas sem substância interna. Coase (1992) afirma que os recursos de um sistema econômico são empregados pelas firmas e são utilizados de acordo com decisões internas, não dependendo diretamente das operações de mercado. De tal forma, ele considera que a eficiência de um sistema econômico depende também de como essa firma conduz seus negócios, principalmente considerando as grandes empresas modernas.

Dentro dessa visão, a evolução do processo industrial, os custos de transação envolvendo determinadas atividades e as próprias mudanças tecnológicas podem melhor explicar as mudanças econômicas surgidas envolvendo o aumento de empresas tecnológicas, em detrimento das empresas industriais, com o consequente aumento de ativos intangíveis na composição das mesmas.

No entanto, não só de mudanças tecnológicas é composto o grupo de ativos intangíveis. De acordo com o CPC 04, são exemplos de elementos que o compõem: softwares, patentes, direitos autorais, direitos sobre filmes cinematográficos, listas de clientes, direitos sobre hipotecas, licenças de pesca, quotas de importação, franquias, relacionamentos com clientes ou fornecedores, fidelidade de clientes, participação no mercado e direitos de comercialização.

Ademais, segundo Gu e Wang (2005), a maioria dos ativos intangíveis não é reconhecida nas demonstrações contábeis e as regras contábeis vigentes à época do estudo não exigiam que as empresas relatassem medidas de desempenhos separadas para os bens intangíveis. Os autores observaram que a alta complexidade de conhecimento sobre os ativos intangíveis aumenta o erro de previsão de informações dos analistas sobre empresas intensivas em tais ativos.

\subsection{Impactos dos ativos intangíveis no valor das empresas}

A avaliação do desempenho das empresas é objetivo dos investidores e outros agentes econômicos usuários das informações contábeis. E nesta análise, os ativos intangíveis são recursos que podem melhorar o desempenho, porque sua diferenciação no processo de construção ou criação de valor pode tornar-se um diferencial competitivo que será traduzido pelo desempenho das empresas ao longo do tempo (CARVALHO et al., 2010).

Nessa mesma linha de entendimento, Lev (2001) já havia destacado que a riqueza e o crescimento na economia seriam conduzidos principalmente pelos ativos intangíveis. Para o autor, ativos físicos e financeiros se transformariam rapidamente em commodities que remunerariam o investimento na média, enquanto que aqueles retornos acima do normal ou melhor posição competitiva poderiam ser obtidos pelo desenvolvimento de ativos intangíveis juntamente com outros tipos de ativos.

Na visão de Teh, Kayo e Kimura (2008), os ativos intangíveis seriam importantes para conferir vantagem competitiva às empresas, de modo a protegê-las das ameaças de eventuais concorrentes, além de possibilitar a manutenção e a expansão no mercado de atuação. Em seus estudos, Lev (2001) apresenta as mudanças econômicas conduzidas desde meados dos anos 1980 e surgidas com o ativo intangível, inovando a combinação exclusiva de duas forças econômicas, sendo a primeira pelo aumento da competição das empresas pela globalização e mudanças na regulação de setores relevantes para a economia (viés econômico) e a segunda pela tecnologia da informação, impulsionada pelo comércio eletrônico mundial (viés tecnológico), alterando significativamente a estruturação das empresas, alavancando os ativos intangíveis como multiplicador do valor das empresas.

Os estudos de Oliveira, Rodrigues e Craig (2010) encontraram como resultado que o lucro líquido, o ágio outros ativos intangíveis são significativamente associados com o preço das ações. Quando as subclasses de ativos intangíveis identificáveis foram consideradas, os autores encontraram evidências de aumento na relevância do valor do ágio, outros intangíveis e despesas de pesquisa e desenvolvimento.

Se há certo consenso de que os intangíveis proporcionam maior valor econômico aos negócios, Machado e Famá (2011) destacam que características do setor de atuação e estratégias implantadas por cada empresa fazem com que os efeitos provocados pelo ativo intangível sejam diferenciados.

Amaral et al. (2014), por sua vez, afirmam que a contabilidade é uma referência para a tomada de decisão 
do gestor, sobretudo a respeito da mensuração de valor ou de lucros e prejuízos que são correlacionados a ativos que podem criar valor e crescimento para a empresa. São ativos que apresentam informações invisíveis que possuem a capacidade de deliberar sobre o preço do produto da empresa, ou seja, são ativos não materializados que geram valorização dos negócios da organização.

\subsection{Revisão de estudos sobre ativos intangíveis}

No intuito de apresentar estudos anteriores sobre o tema de ativos intangíveis e quais foram os resultados obtidos até então, essa seção traz algumas das pesquisas realizadas tanto em âmbito internacional, quanto em âmbito nacional. Na literatura internacional são encontrados vários estudos sobre ativos intangíveis, como os de Choi, Kwon e Lobo (2000), Lev (2001), Sveiby (2001), Knott, Bryce e Posen (2003) e Whitwell, Lukas e Hill (2006), Jones (2011), Basso (2013) e Arif (2013).

Choi, Kwon e Lobo (2000) analisaram a relação entre o valor dos ativos intangíveis, a despesa de amortização associada e valores de mercado das ações das empresas. Os resultados empíricos, baseados na análise das carteiras, indicaram que o mercado responde positivamente a itens de ativos intangíveis reportados no balanço patrimonial, mas não reage de modo significativo a despesas de amortização, não demonstrando relação positiva com o retorno das ações. Tal estudo corroborou com as considerações presentes no Resource-Based View (RBV)perspectiva de estratégia que explica a vantagem competitiva a partir dos recursos e competências distintivos da firma.

Lev (2001) associou principalmente aos ativos intangíveis o crescimento atual das empresas e relacionou o valor das empresas em relação ao seu valor patrimonial líquido, utilizando a taxa do market-to-book das 500 empresas que compõem o índice S\&P. Os estudos de Lev (2001) são referenciados na maior parte das pesquisas atuais sobre ativos intangíveis e sua relação com o valor da empresa. O estudo de Sveiby (2001) focou na mensuração dos ativos intangíveis utilizando o termo capital intelectual para a criação de valor ao acionista, destacando a incapacidade de um sistema de mensuração contábil mensurar fenômenos sociais, mas apresentando diversas formas de possibilitar a identificação dos ativos intangíveis. Villalonga (2004), inovou ao associar a persistência dos lucros das empresas a uma maior intangibilidade dos recursos.

Outros autores que contribuíram para as pesquisas que envolvem o ativo intangível foram Knott, Bryce e Posen (2003). Eles testaram a contribuição do estoque de ativos intangíveis para uma função de produção ótima e examinaram em que medida tal estoque de ativos impede movimentações desses recursos para os rivais na indústria farmacêutica. Os resultados mostraram que o processo de acumulação de ativos intangíveis, por si só, não detém tal mobilidade para os rivais, pois os estoques de ativos alcançam um estado estacionário muito rapidamente. Empresas entrantes poderiam alcançar o nível de ativo intangível de um operador antigo simplesmente combinando seu investimento até o estado estacionário, mas através dos ativos intangíveis obtém retornos acima dos normais. Conclui-se que o processo de acumulação de ativos intangíveis por si só não é um mecanismo de isolamento numa posição vantajosa no mercado.

Ainda nos estudos da importância do RBV, Whitwell, Lukas e Hill (2006) investigaram uma série de fatores antecedentes que poderiam afetar a precisão de analistas na avaliação dos ativos intangíveis no período pós-crise WordCom, Enron e outras. No entanto, os autores chegaram à conclusão de que os analistas de ações não compreendem plenamente a capacidade de geração de riqueza por ativos intangíveis e, por diversas razões, acabam por excluí-los de suas avaliações ou recomendações. A sugestão mais imediata derivada do estudo é que os analistas devem atualizar regularmente seus modelos de avaliação para capturar a relação entre ativos intangíveis e a geração de riqueza. Tais resultados lançam desafio aos analistas de combinar o foco do micro, de uma análise especializada, com uma apreciação de tendências de longo prazo, visualizando as forças motrizes do ambiente macro empresarial.

Em uma outra perspectiva, Jones (2011) inovou ao avaliar a capitalização dos ativos intangíveis em uma perspectiva de associação com indicativos de falência, onde os gestores utilizavam da capitalização dos ativos intangíveis com forma de melhorar o desempenho da empresa, observando também a necessidade de se avaliar as regras utilizadas para reconhecimento destes ativos.

Basso et al (2013) analisou a contribuição dos ativos intangíveis para o valor das empresas, utilizando a metodologia proposta por Gu e Lev (2011), que associa a performance da empresa a ativos físicos, ativos financeiros e ativos intangíveis. Seus resultados, baseados em pesquisa econométrica robusta com muitas variáveis associadas ao desempenho e aos fluxos das empresas gerados pelos capitais intangíveis, apresentaram relação significativa 
entre valor abrangente e valor de mercado, concluindo que a variável explica o valor de mercado, se apresentando como solução para a contabilização dos ativos intangíveis.

Ariff (2013) investigou a divulgação voluntária de informações sobre ativos intangíveis em oito países do Leste Asiático, demonstrando sua relevância nos resultados e demonstrações das empresas de outra região e de outros mercados, diferentemente dos artigos anteriores, e chegando a resultados semelhantes sobre a relevância das pesquisas sobre ativos intangíveis.

No Brasil, embora em um estágio inferior ao observado na literatura internacional, verifica-se tendência de aumento das pesquisas envolvendo a temática dos ativos intangíveis, principalmente após a publicação da Lei 11.638 de 28 de dezembro de 2007, pela obrigatoriedade do registro do grupo de Ativos Intangíveis, equiparando a legislação brasileira às práticas contábeis internacionais. Ritta et al. (2010) destaca que antes desse período, algumas pesquisas no Brasil já tratavam do tema, pois empresas brasileiras listadas no exterior já vinham utilizando o conceito de ativos intangíveis em suas demonstrações desde 2001.

Kayo (2002) examinou as diferenças de estrutura de capital e de risco entre as empresas tangível e intangível-intensivas. O resultado da pesquisa demonstrou que a estrutura de capital parece ser o fator mais importante na diferenciação entre os dois tipos de empresas, evidenciando que aquelas intensivas em capital intangível apresentam, do ponto de vista financeiro, diferenças significativas em relação às empresas intensivas em capital tangível. A pesquisa de Kayo (2002) utilizou os estudos de Lev (2001), entre outros, criando sua própria metodologia, utilizando algumas das variáveis utilizadas nesta pesquisa. Em outro artigo desta pesquisa sobre estrutura de capital das empresas, Kayo e Famá (2004) examinaram as características financeiras de empresas intensivas em ativos tangíveis e as intensivas em ativos intangíveis, usando como indicador o nível de intangibilidade, medido pela relação entre o valor de mercado da empresa dividido pelo patrimônio líquido contábil. Os resultados da pesquisa mostraram que as empresas intensivas em ativos intangíveis apresentaram, em média, menor nível de endividamento, porém essas mesmas empresas tenderam a apresentar um maior custo médio ponderado de capital.

Ritta et al. (2010) pesquisaram sobre a relação entre os ativos intangíveis e as variáveis financeiras nas empresas brasileiras pertencentes ao Índice Ibovespa nos anos de 2007 e 2008 utilizando duas variáveis: índice de investimentos em ativos intangíveis, obtido pelo total dos ativos intangíveis em relação ao patrimônio líquido, e o índice de intangibilidade, obtido pela relação entre valor de mercado e patrimônio líquido. Os resultados encontraram correlação positiva entre os investimentos realizados em ativos intangíveis e o índice de intangibilidade das empresas, sendo que as análises de regressão foram significativas e apontaram relação positiva entre os ativos intangíveis e as variáveis financeiras propostas: receita líquida, patrimônio líquido e valor de mercado. A partir da análise dos estudos de Kayo (2002) e de Ritta et al (2010) é que surgiu a forma inovadora de se apurar a variável dependente IIA, apurado pela divisão do montante de ativo intangível pelo ativo total.

Nascimento et al (2012) estudaram a correlação existente entre o impacto do grau de intangibilidade (GI), apurado pela diferença entre o valor patrimonial contábil e o valor de mercado, e indicadores de desempenho, entre eles o Retorno sobre Patrimônio Líquido (ROE) e Retorno sobre Ativos (ROA), das empresas de tecnologia da informação e telecomunicações, concluindo não haver diferenças entre os segmentos analisados e que o ROA não apresentou correlação significativa.

Zago, Mello e Rojo (2013), por exemplo, buscaram avaliar a influência dos ativos intangíveis no desempenho das empresas listadas no Índice Bovespa, nos anos de 2011 e 2012. Eles verificaram a relação entre o grau de intangibilidade (GI) e grau de intangibilidade médio (GIM) e os indicadores de desempenho como a rentabilidade sobre o ativo (ROA), a rentabilidade sobre o patrimônio líquido (ROE) e a rentabilidade sobre o investimento (ROI). Os resultados identificados pelos autores evidenciaram que o grau de intangibilidade não apresentou influência significativa sobre o desempenho das empresas.

O estudo realizado por Leite e Santos (2013) se concentrou na valoração dos ativos intangíveis das cinco maiores empresas da indústria de materiais básicos (IMAT) do Brasil, no período de 2005 a 2010, e na análise da influência destes no valor de mercado das empresas. Os resultados descritivos da pesquisa não foram convergentes a despeito da valoração dos intangíveis das firmas durante o período analisado. No entanto, observou-se que o excedente de retorno dos ativos foi significativo e com estimativas superiores aos ativos tangíveis, porém com maior volatilidade.

Perez e Famá (2015) apresentaram as características estratégicas dos ativos intangíveis na atual sociedade, concluindo que estes ativos são relevantes para a geração de valor por promover um desempenho econômico superior nas empresas que destinam parcela maior de recursos para investimentos em ativos intangíveis, demonstrando sua importância estratégica para aumento da riqueza do negócio. Em resumo, pelo observado nos 
estudos realizados, existe uma lacuna teórica na literatura nacional a ser preenchida sobre o impacto da presença de ativos intangíveis para o valor de mercado das empresas, controlando sua capacidade explicativa por meio de outras variáveis financeiras e de mercado. Em termos empíricos, tais efeitos ainda não estão consolidados.

Considerando o exposto, notadamente quanto à perspectiva de que os ativos intangíveis agregam valor e resultados anormais, bem como nos resultados de estudos como os de Lev (2001), Ritta et al. (2010) e Zago et al. (2013) e Perez e Famá (2015), entre outros, é possível inferir que empresas que intensificam seus recursos em ativos intangíveis sejam melhor avaliadas pelo mercado, na precificação das suas ações. O pressuposto é que modelos de negócio baseados significativamente em conhecimento e tecnologias devem promover vantagens competitivas, o que deve se refletir no valor de mercado das empresas. Nesse sentido, é formulada a seguinte hipótese de pesquisa, a ser testada empiricamente:

$\mathrm{H}_{1}$ : No âmbito do mercado de capitais brasileiro, as companhias que integram o IBrX apresentam relação positiva ente o nível de intangibilidade dos ativos e o market-to-book.

\section{PROCEDIMENTOS METODOLÓGICOS}

Como destacado anteriormente, o propósito do presente estudo é avaliar, no âmbito do mercado de capitais brasileiro, a associação entre o valor de mercado das empresas e o nível de intangibilidade dos ativos. Para testar empiricamente a hipótese H1, é importante definir, objetivamente, o modelo econométrico e a amostra para a realização dos testes.

\subsection{Definição do modelo}

Para testar empiricamente os efeitos determinantes da relação prevista na hipótese de pesquisa $H_{1}$, é especificado o modelo (3.1), que será a base dos testes empíricos, com o uso de dados em painel, que segundo Marques (2000), providenciam maior quantidade de informação, maior variabilidade dos dados, menor colinearidade entre as variáveis, maior número de graus de liberdade e maior eficiência na estimação.

$$
M T B_{i t}=\beta_{o}+\beta_{1} I I A_{i t}+\beta_{2} R O E_{i t}+\beta_{3} I F I N_{i t}+\beta_{4} E B I T D A_{i t}+\beta_{5} T A M_{i t}+\beta_{6} I B O V_{t}+\varepsilon_{i t}
$$

Em que:

$\mathrm{MTB}_{\mathrm{it}}$ : é a relação entre o valor de mercado e o valor contábil (valor do patrimônio líquido) - marketto-book - em que o valor de mercado é obtido pela multiplicação do valor da cotação da ação pela quantidade de ações da empresa i, no período t;

IIA $A_{i t} \quad$ corresponde ao índice de intangibilidade dos ativos, apurado pela divisão do montante de ativo intangível pelo ativo total da empresa i, no momento t;

$\mathrm{ROE}_{\mathrm{it}} \quad$ mede o retorno gerado sobre o patrimônio líquido - return on equity - da empresa i, no momento t; calculado pela divisão entre o lucro líquido (após impostos) e o patrimônio líquido, expressando a capacidade de agregação de valor para o acionista;

IFIN $_{\text {it }}$ : é a estrutura de financiamento da empresa i no momento t, apurada pela razão entre o valor total das dívidas financeiras e o valor total de ativos representando a participação das dívidas de curto e longo prazo na estrutura patrimonial da empresa;

EBITDA $_{\mathrm{it}}$ : corresponde ao lucro antes dos juros, do imposto de renda, depreciações/exaustões e amortizações, dividido pelos ativos totais, da empresa i, no momento t;

$\mathrm{TAM}_{\mathrm{it}}$ : é medida de tamanho, apurada em função do logaritmo natural dos ativos totais da empresa i no 
momento t;

$\mathrm{IBOV}_{\mathrm{t}}$ : é o logaritmo natural do índice Ibovespa, no momento $\boldsymbol{t}$

Para o teste da hipótese $\mathrm{H}_{1}$, a variável de interesse é IIA, que representa o grau de intangibilidade dos ativos. A hipótese de pesquisa é corroborada se essa variável apresentar relação positiva e estatisticamente relevante com a variável dependente (MTB). Nesse caso, seria confirmada a relação positiva entre o grau de intangibilidade dos ativos e o valor de mercado da empresa, relativamente ao valor contábil. Além da variável de interesse, foram incorporadas variáveis de controle no modelo de estimação: ROE, IFIN, EBITDA, TAM e IBOV. A consideração dessas variáveis funciona como um elemento de robustez dos potenciais achados, na medida em que são controlados os efeitos do retorno sobre o capital investido, do grau de alavancagem financeira, do tamanho da entidade e do comportamento do mercado de capitais na definição do valor da entidade.

O ROE é um indicador financeiro que reflete a capacidade da empresa em agregar valor a ela mesma, utilizando os seus próprios recursos. É esperado, portanto, que maiores índices de retorno sobre o capital próprio se reflitam positivamente no valor de mercado. Já o IFIN representa o grau de alavancagem financeira das empresas e traduz a capacidade de, a partir da utilização de recursos de terceiros, agregar valor à empresa. Nesse sentido, baseado na premissa de risco e retorno, é esperada relação positiva entre o nível de endividamento e o valor de mercado. O EBITDA é utilizado essencialmente para analisar o desempenho das organizações, pois reflete uma proxy da capacidade de geração de caixa operacional, devendo ser precificado positivamente pelo mercado. A variável TAM foi incorporada no modelo com o propósito de capturar os efeitos da variável tamanho da empresa no valor de mercado das empresas. Por fim, o IBOV representa o índice de mercado do qual as variáveis fazem parte, sendo esperada uma relação positiva com a variável dependente (MTB), considerado que o valor de mercado das empresas seria influenciado pelo desempenho médio das cotações de ações negociadas.

Tais variáveis, utilizadas conjuntamente para testar os efeitos do IIA em MTB é uma inovação proposta pelo modelo em relação a estudos anteriores. Cunha, Campos e Longhi (2015) estudaram se o preço das ações pode ser explicado pelas variáveis Lucro Líquido (LL), Patrimônio Líquido (PL), Tamanho (TAM), Endividamento (END), Market-to-book (MTB) e Free float (FREEFLOAT) para as empresas que fazem parte da carteira do Índice de Sustentabilidade Empresarial (ISE). Apenas o PL, LL e FREEFLOAT foram estatisticamente significativos.

Gilio (2010) relacionou MTB com IIA (acrescentado de ágio e diferido) encontrando relação negativa não significativa. Camargos, Camargos e Rachumi (2009) fez estudo comparativo do poder explicativo acionário, para identificar se as variáveis da Análise Financeira Tradicional (AFT) e da Análise Dinâmica explicam o retorno acionário, concluindo que o primeiro tem maior poder de explicação. No estudo usou, entre outras, as variáveis, ROE, TAM e EBITDA representadas por fatores.

\subsection{Amostra de dados}

Para a realização dos testes empíricos foram consideradas as informações trimestrais, de 2008 a 2014, coletados no software da Thomson Reuters, referentes às empresas que compõem o índice IBrX $100 \mathrm{da}$ BM\&FBovespa. A utilização da referência do IBrX - Índice Brasil se justifica por ser um índice de preços que mede o retorno da carteira teórica composta por 100 ações selecionadas entre as mais negociadas na BM\&FBovespa, em termos de número de negócios e volume financeiro. Essas ações são ponderadas na carteira do índice pelo seu respectivo número de ações disponíveis à negociação no mercado. Nesse sentido, a escolha decorre da relevância das empresas que compõem a carteira, pois o índice é composto por companhias abertas que estão entre as 100 melhores classificadas quanto ao seu índice de negociabilidade, apurados nos doze meses anteriores à reavaliação, e cumulativamente, que foram negociadas em pelo menos $70 \%$ dos pregões ocorridos nos doze meses anteriores à formação da carteira.

Em relação ao período, a escolha de considerar dados a partir de 2008 se justifica pelo início da vigência da Lei n ${ }^{\circ} 11.638 / 07$ e do pronunciamento do CPC 04, que definiu o tratamento contábil dos ativos intangíveis que não eram abrangidos especificamente em outros pronunciamentos, promovendo uma uniformização quanto ao seu reconhecimento, mensuração e evidenciação nas empresas sujeitas a estes normativos, que representam a maior parte do mercado de capitais no período considerado. Apesar da existência de normativos anteriores, como por exemplo a Deliberação CVM no 488 de 03/10/2005, que orientava a inclusão do grupo ativo intangível na apresentação das demonstrações contábeis, as orientações específicas sobre reconhecimento e mensuração somente foram apresentadas na Lei n ${ }^{\mathrm{o}} 11.638 / 07$ e CPC 04. 


\section{ANÁLISE DOS RESULTADOS}

Considerando os propósitos do estudo, a análise de resultados é apresentada em duas etapas: a análise das estatísticas descritivas e a análise de regressão, por meio de dados em painel. Levantadas as variáveis que compõem o modelo (3.1), a primeira etapa do processo de análise foi a apuração das estatísticas descritivas, sintetizadas na Tabela 1, evidenciando que as variáveis IBOV, TAM, IFIN e EBITDA mostram valores de medidas de tendência central (média, mediana) bem próximos. Com relação à medida de variabilidade, representada pelo desvio padrão, mostram valores pequenos se apresentado com curvas mais afiladas, pela interpretação do indicador de curtose, com exceção da variável IFIN que está mais próxima de uma curva achatada (platicúrtica). Para as demais variáveis MTB, IIA e ROE, análise inversa se verifica com relação às medidas centrais e de variabilidade, mas concordante com relação à curtose.

Tabela 1. Estatísticas descritivas das variáveis do modelo (3.1)

\begin{tabular}{lccccccc}
\hline Estatísticas & MTB & ROE & IIA & IFIN & EBITDA & TAM & IBOV \\
\hline Média & 3,1014 & 0,1861 & 0,1589 & 0,3104 & 0,1396 & 16,2968 & 10,9456 \\
Mediana & 1,8000 & 0,1529 & 0,0682 & 0,3188 & 0,1258 & 16,2989 & 10,9465 \\
Máximo & 52,0100 & 1,7933 & 0,8795 & 0,6986 & 0,8386 & 21,0862 & 11,1615 \\
Mínimo & 0,1000 & $-0,7455$ & 0,0000 & 0,0000 & $-0,1595$ & 11,6543 & 10,5334 \\
Desvio padrão & 4,3946 & 0,2302 & 0,2089 & 0,1642 & 0,0941 & 1,8242 & 0,1522 \\
Assimetria & 4,6612 & 2,7718 & 1,6535 & $-0,0789$ & 1,6249 & 0,4325 & $-0,6265$ \\
Curtose & 32,5780 & 17,8399 & 4,9362 & 2,4752 & 10,1653 & 3,5231 & 3,2123 \\
\hline
\end{tabular}

Nota: MTB - relação entre valor de mercado e valor do patrimônio líquido contábil - market-tobook; IIA índice de intangibilidade dos ativos; ROE mede o retorno gerado sobre o patrimônio líquido - return on equity; IFIN - estrutura de financiamento; EBITDA - lucro antes dos juros, do imposto de renda, depreciações/exaustões e amortizações, dividido pelos ativos totais; TAM medida de tamanho; IBOV - logaritmo natural do índice Ibovespa..

Preliminarmente à estimação do modelo (3.1), foram adotados procedimentos no sentido de verificar o atendimento às condições para assegurar a robustez dos achados. Confirmada a condição de normalidade, conforme destacado na Tabela 1, foram avaliados e tratados os riscos de multicolinearidade e de autocorrelação e de heterocedasticidade nos resíduos.

Para o diagnóstico do risco de multicolinearidade, foi realizado o teste de inflação de variância entre as variáveis independentes, sugerido por Kennedy (1998) e Gujarati (2006). Os Fatores de Inflação de Variância (FIV) apurados a partir de regressões auxiliares entre cada variável independente (j-ésima) e os demais regressores restantes do modelo, são demonstrados na Tabela 2.

Tabela 2. Resultados dos testes de inflação de variância entre as variáveis independentes

\begin{tabular}{cccccc}
\hline $\begin{array}{c}\text { j-ésima } \\
\text { variável }\end{array}$ & $\begin{array}{c}\mathbf{R}^{2} \text { regressão } \\
\text { auxiliar }\end{array}$ & FIVj & $\begin{array}{c}\text { j-ésima } \\
\text { variável }\end{array}$ & $\begin{array}{c}\mathbf{R}^{2} \text { regressão } \\
\text { auxiliar }\end{array}$ & FIVj \\
\hline IIA & 0,0095 & 1,0096 & EBITDA & 0,1887 & 1,2298 \\
ROE & 0,1182 & 1,1341 & TAM & 0,1050 & 1,1173 \\
FIN & 0,0647 & 1,0692 & IBOV & $-48,6126$ & 0,0202 \\
\hline
\end{tabular}

Nota: IIA índice de intangibilidade dos ativos; ROE mede o retorno gerado sobre o patrimônio líquido - return on equity; IFIN - estrutura de financiamento; EBITDA - lucro antes dos juros, do imposto de renda, depreciações/exaustões e amortizações, dividido pelos ativos totais; TAM - medida de tamanho; IBOV - logaritmo natural do índice Ibovespa. 
sérios de multicolinearidade se algum dos FIV for maior que 10, os resultados destacados na Tabela 2 demonstram que esse não é o caso do presente estudo.

Na estimação do modelo (3.1) com o uso de dados em painel e o método dos mínimos quadrados ordinários foram identificadas evidências de autocorrelação nos resíduos. Para lidar com esse problema e evitar o risco de heterocedasticidade foram desprezadas as estimações pelo método OLS, optando-se por utilizar parâmetros robustos, com o uso do método SUR (PCSE). Nesse caso, são gerados parâmetros robustos, mesmo na presença de autocorrelação e de heterocedasticidade nos resíduos. Ademais, devido a valores extremos observados nas estatísticas descritivas, foram feitos testes adicionais excluindo as observações que se distanciam mais ou menos cinco desvios padrões em relação à média.

Considerando essas definições, foram promovidas quatro estimações do modelo (3.1), com dados em painel e método SUR (PCSE), combinando a utilização das bases completa e sem os outliers com o uso de efeitos fixos seccionais e de duplo efeitos fixos - que controlam, respectivamente, a heterogeneidade entre as empresas e entre empresas e períodos, concomitantemente. O propósito de usar essa combinação de técnicas de estimação se justifica pela conveniência de se verificar se os resultados apurados são resilientes a diferentes formas de estimação, o que representa uma espécie de análise de sensibilidade. Os resultados são sintetizados na Tabela 3.

Tabela 3. Estimação do modelo (3.1) com dados em painel e efeitos fixos seccionais e duplo efeitos fixos

\begin{tabular}{|c|c|c|c|c|}
\hline & \multicolumn{2}{|c|}{ Base completa } & \multicolumn{2}{|c|}{ Base sem outliers } \\
\hline & EF Seccionais & Duplo EF & EF Seccionais & Duplo EF \\
\hline & $-1,5748$ & 7,7824 & $-0,8738$ & 7,4219 \\
\hline Const & $(0,7803)$ & $(0,0000)^{* * *}$ & $(0,8528)$ & $(0,0000)^{* * *}$ \\
\hline & 0,8701 & 1,0282 & 0,9288 & 0,8711 \\
\hline IIA & $(0,0077)^{* * *}$ & $(0,0027)^{* * *}$ & $(0,0023)^{* * *}$ & $(0,0031)^{* * *}$ \\
\hline & 0,5768 & 0,5885 & 1,8331 & 2,2323 \\
\hline ROE & $(0,0000)^{* * *}$ & $(0,0000) * * *$ & $(0,0044)^{* * *}$ & $(0,0005)^{* * *}$ \\
\hline & 6,7571 & 6,2981 & 5,3960 & 5,2608 \\
\hline IFIN & $(0,0000)^{* * *}$ & $(0,0000)^{* * *}$ & $(0,0000)^{* * *}$ & $(0,0000)^{* * *}$ \\
\hline & 13,6124 & 14,0179 & 7,6780 & 7,2462 \\
\hline EBITDA & $(0,0000)^{* * *}$ & $(0,0000)^{* * *}$ & $(0,0000)^{* * *}$ & $(0,0000) * * *$ \\
\hline & $-0,4079$ & $-0,5498$ & $-0,2458$ & $-0,4809$ \\
\hline TAM & $(0,0092)^{* * *}$ & $(0,0000)^{* * *}$ & $(0,0644)^{*}$ & $(0,0000)^{* * *}$ \\
\hline & 0,6383 & & 0,4039 & \\
\hline IBOV & $(0,1901)$ & & $(0,2933)$ & \\
\hline $\mathrm{N}^{\mathrm{o}}$ entidades & 86 & 86 & 86 & 86 \\
\hline Período & 28 trimestres & 28 trimestres & 28 trimestres & 28 trimestres \\
\hline $\mathrm{N}^{0}$ observações & 2.158 & 2.158 & 2.133 & 2.133 \\
\hline $\mathrm{R}^{2}$ & 0,7820 & 0,7915 & 0,8219 & 0,8323 \\
\hline $\mathrm{R}^{2}$ Ajustado & 0,7724 & 0,7796 & 0,8139 & 0,8225 \\
\hline Estatística F & 81,4428 & 66,2015 & 103,5161 & 85,4829 \\
\hline F (p-valor) & 0,0000 & 0,0000 & 0,0000 & 0,0000 \\
\hline
\end{tabular}

Nota: MTB - relação entre valor de mercado e valor do patrimônio líquido contábil - market-to-book; IIA índice de intangibilidade dos ativos; ROE mede o retorno gerado sobre o patrimônio líquido - return on equity; IFIN - estrutura de financiamento; EBITDA - lucro antes dos juros, do imposto de renda, depreciações/exaustões e amortizações, dividido pelos ativos totais; TAM - medida de tamanho; IBOV logaritmo natural do índice Ibovespa..

Nível de Significância: *** 1\%;** 5\%; * 10\%. P-valores entre parênteses. 
Os resultados dos testes demonstrados na Tabela 3 revelam, nos quatro testes realizados - com efeitos fixos seccionais ou duplo efeitos fixos, utilizando os métodos de estimação de parâmetros robustos SUR (PCSE), e com base completa e base sem outliers - a associação positiva e estatisticamente relevantes entre a variável dependente MTB e a variável de interesse IIA. Esses resultados confirmam as expectativas de que o mercado precifica positivamente o grau de intangibilidade dos ativos, ou seja, que as ações das empresas intensivas em ativos intangíveis registram melhor relação market-to-book que as demais. É corroborada, assim, a hipótese de pesquisa $\mathrm{H}_{1}$.

Estes resultados confirmam evidências relatadas por Ritta et al. (2010) quanto à relação positiva entre os investimentos em ativos intangíveis, índice de intangibilidade e variáveis financeiras. Também corroboram com o estudo de Lev (2001), que demonstrou que os investimentos em ativos intangíveis impactam o valor de mercado das empresas, pois a evidenciação dos investimentos em ativos intangíveis é capturada pelo mercado que precifica esta avaliação.

As evidências empíricas do presente estudo também reforçam os achados de Choi et al. (2000), Kayo (2002) e Teh et al. (2008) quanto à demonstração da relevância dos ativos intangíveis na melhoria da posição competitiva e sua influência sobre o desempenho das empresas, representado pelo valor de mercado. Por fim, também corroboram a afirmação de Carvalho et al. (2007), no sentido de que os efeitos da intangibilidade devem ser tratados de forma complementar com outros fatores, com a utilização de variáveis de controle.

Os achados da presente pesquisa permitem avançar na teoria sobre valor de mercado adquirido com a presença de ativos intangíveis por meio desse novo modelo que utiliza uma variável explicativa representada por ativos intangíveis relativizados pelo total de ativos das empresas e controlados com variáveis financeiras e de mercado já utilizadas em estudos anteriores.

Em relação à primeira das variáveis de controle, os resultados demonstram, também nas quatro estimações, que há associação positiva entre o market-to-book (MTB) e o retorno sobre o patrimônio liquido (ROE). Considerando que o ROE é uma medida de performance da companhia, que evidencia se a entidade está gerando rentabilidade para os acionistas, Nesse sentido, a associação positiva evidenciada empiricamente é intuitiva e compatível com o que seria esperado do comportamento dos investidores.

No que se refere à variável representativa do grau de alavancagem financeira (IFIN) das empresas, os resultados também demonstraram relação positiva com a variável dependente, MTB, nas quatro estimações realizadas. Tendo em vista a natureza da alavancagem financeira, que consiste em obter recursos de terceiros para investir ou realizar operações, potencializando o retorno dos acionistas, a relação positiva encontrada pode ser definida como natural. Em síntese, o mercado precifica positivamente as ações de empresas alavancadas, considerando a perspectiva de melhorar o retorno dos proprietários. É evidente que o benefício do endividamento tem limites, pois a partir de determinado nível a percepção de risco dos credores em relação à empresa pode impactar o custo do capital.

Para a variável EBITDA, representativa da capacidade de geração de caixa operacional, os resultados demonstrados na Tabela 3 também revelaram associação positiva a variável dependente MTB. Isso demonstra que os investidores valorizam as empresas capazes de gerar caixa operacional, o que é justificável, tendo em vista que traduz a capacidade da empresa em honrar as suas obrigações contratuais, gerar resultados e distribuir dividendos.

O impacto do tamanho das empresas (TAM) na relação market-to-book também foi avaliado como elemento de controle para os testes da hipótese $\mathrm{H}_{1}$. Nesse caso, os resultados demonstraram que há associação negativa entre as variáveis MTB e TAM, ou seja, quanto maior a empresa, menor a relação market-to-book. Uma das possibilidades para esse resultado pode se depreender da afirmação de Nunes (2010), no sentido de que grandes empresas sofrem pressão de várias partes interessadas nas suas atividades, com maiores custos políticos e utilizam eventualmente técnicas para desviar a atenção que pode afetar seus resultados. Isso pode afetar a relação market-to-book dessas entidades.

Também foi testado, como elemento de controle, os eventuais efeitos do comportamento do Ibovespa na relação market-to-book das empresas que integram o IBrX 100. Essa variável só foi considerada nas estimações com efeitos fixos seccionais, tendo em vista que o efeito temporal, inerente à variável IBOV, já é capturado nas estimações com duplo efeitos fixos. Contrariamente à previsão inicial de associação positiva entre as variáveis, os resultados dos testes demonstraram não haver relação estatisticamente relevante entre elas. Entre os elementos que podem justificar esses resultados contra intuitivos pode se aventar as eventuais características das empresas que compõem o IBrX 100.

Por fim, há que se ressaltar o fato de que as quatro estimações do modelo (3.1) demonstraram coerência em relação aos sinais e à relevância estatística das variáveis. Ainda sobre as estimações, os coeficientes de determinação 
$\left(\mathrm{R}^{2}\right)$ das regressões demonstram que os modelos explicam entre 78,20\% e 83,23\% do comportamento do MTB, o que vem a ser validado pelas estatísticas $\mathrm{F}$, que confirmam a significância conjunta dos parâmetros das variáveis independentes com relação à variável dependente com p-valores ínfimos $(0,0000)$.

\section{CONSIDERAÇÕES FINAIS}

O objetivo central deste estudo foi avaliar se há associação entre o nível de intangibilidade dos ativos e a valorização das empresas no âmbito do mercado de capitais brasileiro, especificamente no intuito de evidenciar se as empresas, ao intensificar seus recursos em ativos intangíveis, são mais valorizadas pelo mercado na avaliação de suas ações.

A hipótese de pesquisa que direcionou a realização dos testes empíricos se fundamenta no pressuposto de que as empresas com modelos de negócio baseados significativamente em conhecimento e tecnologias devem assegurar vantagens competitivas que são percebidas pelo mercado e traduzidas na valorização das ações dessas companhias.

Os testes empíricos, que tiveram por base as informações trimestrais de 2008 a 2014 das empresas que compõem o índice IBrX 100 da BM\&FBovespa, confirmaram a associação positiva e estatisticamente relevante entre o market-to-book e o índice de intangibilidade dos ativos, corroborando a hipótese de pesquisa e reforçando formulações teóricas e evidências empíricas de estudos anteriores.

De forma geral, os resultados dos testes demonstram a relevância dos investimentos em ativos intangíveis sobre o valor de mercado das empresas, reforçando a percepção de que o ambiente econômico das empresas com características baseadas em conhecimento e tecnologias, mantendo suas vantagens competitivas e aumentando o valor das ações. A premissa é que a maior participação dos ativos intangíveis na estrutura patrimonial aumenta a perspectiva de geração de lucros anormais. O que dá sustentação a esse argumento é que enquanto os ativos tangíveis, pela sua disponibilidade no mercado, produzem o retorno pela média, cabe aos intangíveis um retorno acima da média, melhorando o posicionamento da empresa no mercado, sendo esta característica percebida pelos acionistas ao se confirmar a correlação das variáveis.

Além das evidências em relação à variável de interesse, as estimações realizadas também contemplaram o exame da relação entre a variável dependente MTB e variáveis de controle. Nesse particular, foi constatado que a MTB apresenta relação: positiva com o retorno sobre o patrimônio líquido, o grau de alavancagem financeira e a capacidade de geração de caixa operacional; e negativa com o tamanho das empresas.

O estudo contribui para o avanço da literatura sobre os determinantes do valor de mercado das empresas em relação ao valor contábil, que tem aumentado significativamente ao longo dos tempos, mas que ainda apresenta oportunidades de desenvolvimento, como é o caso dos impactos dos ativos intangíveis. Corrobora outros trabalhos acadêmicos sobre o tema, ampliando o período amostral e utilizando todas as informações disponíveis das empresas que compõem o índice IBrX desde a introdução do grupo contábil representativo dos ativos intangíveis na estrutura das demonstrações contábeis das companhias abertas brasileiras - Lei 11.638/2007. Avança por meio dos resultados obtidos sobre relevância dos ativos intangíveis para o valor de mercado das empresas utilizando modelo inovador com variáveis de controle para testar os efeitos do IIA em MTB.

Se o período amostral, de 2008 a 2014, foi destacado como um fator de relevância do estudo, por ampliar a abrangência de estudos anteriores, também pode ser entendido como limitação, na medida em que o histórico de informações sobre os ativos intangíveis é relativamente curto para se firmar conclusões definitivas sobre a relação estudada. Também é possível se destacar a limitação quanto à comparação com estudos realizados em âmbito internacional, tendo em vista as diferenças estruturais quanto à liquidez e consolidação dos mercados de capitais em economias mais desenvolvidas comparativamente à realidade brasileira.

\section{REFERÊNCIAS}

AMARAL, H. F.;et al. Avaliação de ativos intangíveis: modelos alternativos para determinação do valor de 
patentes. Revista de Gestão, Finanças e Contabilidade, v. 4, n. 1, p. 123-143, 2014.

ARIFF, A. M.; CAHAN, S. F.; EMANUEL, D. M. Institutional Environment, Ownership, and Disclosure of Intangibles: Evidence from East Asia. Journal of International Accounting Research, v. 13, n. 1, p. 33-59, 2013.

BASSO, L. F. C.et al. The impact of intangibles on value creation: Comparative analysis of the Gu and Lev methodology for the United States software and hardware sector. Investigaciones Europeas de Dirección y Economía de la Empresa, 21(2), 73-83, 2015.

CAMARGOS, M. A.; COUTINHO, E. S. A Teoria da Firma e a Fundamentação Teórica para Fusões e Aquisições: uma análise de suas interfaces. RAC-Eletrônica, v. 2, n. 7, p. 273-295, 2008.

CAMARgos, M. A.; CAMARgOS, M. C. S.; RACCHUMI, J. A. R. Análise financeira tradicional e análise dinâmica: um estudo comparativo do poder de explicação do retorno acionário. In: XXIX ENCONTRO NACIONAL DE ENGENHARIA DE PRODUÇÃO, Salvador. Anais... Salvador: ENEGEP, 2009.

CARVALHO, F. M.; KAYO, E. K.; MARTIN, D. M. L. Tangibilidade e intangibilidade na determinação do desempenho persistente de firmas brasileiras. Revista de Administração Contemporânea, v. 14, n. 5, p. 871889, 2010.

CHOI, W. W.; KWON, S. S.; LOBO, G. J. Market valuation of intangible assets. Journal of Business Research, v. 49, n.1, p. $35-45,2000$.

COASE, R. H. The institutional structure of production. The American Economic Review, v. 82, n. 4, p. 713-719, 1992.

COLAUTO, R.D.; NASCIMENTO, P.S.; AVELINO, B.C. Evidenciação de ativos intangíveis não adquiridos nos relatórios da administração das companhias listadas nos níveis de governança corporativa da Bovespa. Contabilidade Vista \& Revista, v. 20, n. 1, p.143-169, 2009.

GILIO, L. Análise da Capacidade Explicativa de Informações Contábeis para o Índice Market-To-Book de Empresas Listadas no IBOVESPA. In CONGRESSO USP DE CONTROLADORIA E CONTABILIDADE, 10., 2010, São Paulo. Anais... São Paulo: USP, 2010.

GU, F.; LEV, B Overpriced Shares, Ill-Advised Acquisitions, and Goodwill Impairment. The Accounting Review, Vol. 86, No. 6, pp. 1995-2022, 2011.

GU, F.; WANG, W. Intangible Assets, Information Complexity, and Analysts' Earnings Forecasts. Journal of Business Finance \& Accounting, v, 32, n. 9 e 10, p. 1673-1701, 2005.

GUJARATI, D. N.; PORTER, D. C. Econometria Básica-4. Porto Alegre: AMGH Editora, 2006.

JONES, S. Does the Capitalization of Intangible Assets Increase the Predictability of Corporate Failure?. Accounting Horizons, v. 25, n. 1, p. 41-70, 2011.

KAYO, E. K. A estrutura de capital e o risco das empresas tangível e intangível-intensivas: uma contribuição ao estudo da valoração de empresas. 110 f. Tese de Doutorado em Administração. Universidade de São Paulo, São Paulo, 2002.

KAYO, E. K.; FAMÁ, R. A estrutura de capital e o risco das empresas tangível-intensivas e intangível-intensivas. Revisa de Administração da USP, São Paulo, v. 39, n. 2, p. 164-176, 2004.

KAYO, E. K. et al. Ativos intangíveis, ciclo de vida e criação de valor. Revista de Administração Contemporânea, v. 10, n. 3, p. 73-90, 2006.

KENNEDY, P. A Guide to Econometrics. 4 ed. Cambridge: Mass, 1998.

KNOTT, A. M.; BRYCE, D. J.; POSEN, H. E. On the strategic accumulation of intangible assets. Organization Science, v. 14, n. 2, p. 192-207, 2003.

LEITE, T. S.; SANTOS, D. F. L. A relação dos ativos intangíveis e o valor de mercado na indústria de materiais básicos do Brasil. Revista Brasileira de Administração Científica, v. 4, n. 1, p. 104-121, 2013.

LEV, B. Intangibles: management, measurement, and reporting. Washington: Brookings, 2001.

MACHADO, J. H.; FAMÁ, R. Ativos Intangíveis e Governança Corporativa no Mercado de Capitais Brasileiro. Revista Contemporânea de Contabilidade, v. 8, n.16, p. 89-110,2011. DOI: 10.5007/2175-8069.2011v8n16p89. 
MARQUES, L. D. Modelos dinâmicos com dados em painel: revisão de literatura. Centro de estudos Macroeconómicos e Previsão, faculdade de Economia do Porto, 2000.

NASCIMENTO, E. M. et al.. Ativos intangíveis: análise do impacto do grau de intangibilidade nos indicadores de desempenho empresarial. Enfoque: Reflexão Contábil, v. 31, n. 1, p. 37-52, 2012.

NUNES, J. G. et al. Análise das variáveis que influenciam a adesão das empresas ao índice BM\&FBOVESPA de sustentabilidade empresarial. BASE-Revista de Administração e Contabilidade da Unisinos, v. 7, n. 4, p. 328-340, 2010.

OLIVEIRA, L.; RODRIGUES, L. L.; CRAIG, R. Intangible assets and value relevance: Evidence from the Portuguese stock exchange. The British Accounting Review, 2, 241-252, 2010.

PEREZ, M.; FAMÁ, R. Características estratégicas dos ativos intangíveis e o desempenho econômico da empresa. Unisanta Law and Social Science, v. 4, n. 2, p. 107-123, 2015.

RITTA, C. D. O.; ENSSLIN, S. R. Investigação sobre a relação entre ativos intangíveis e variáveis financeiras: um estudo nas empresas brasileiras pertencentes ao Índice Ibovespa nos anos de 2007 e 2008 . In: Congresso USP de Controladoria e Contabilidade, 10, 2010, São Paulo. Anais...São Paulo: USP, p. 1-16, 2010

SVEIBY, K. E. Methods for measuring intangible assets. Disponível em: http://www.sveiby.com/articles/ IntangibleMethods.htm. Acesso em: 30/01/2015.

TEH, C. C.; KAYO, E. K.; KIMURA, H. Marcas, patentes e criação de valor. Revista de Administração Mackenzie, v. 9, n. 1, p. 86-106, 2008.

TIGRE, P. B. Paradigmas tecnológicos e teorias econômicas da firma. Revista Brasileira de Inovação, v. 4, p. 187-223, 2005.

WHITWELL, G. J.; LUKAS, B. A.; HILL, P. Stock analysts' assessments of the shareholder value of intangible assets. Journal of Business Research, v. 60, n.1, p. 84-90, 2007.

ZAGO, C.; MELLO, G. R.; ROJO, C. A. Influência dos ativos intangíveis no desempenho das empresas listadas no índice Bovespa. Revista de Finanças e Contabilidade da Unimep, v. 2, n. 2, p. 92-107, 2015. 